\title{
An integrated DRASTIC model using frequency ratio and two new hybrid methods for groundwater vulnerability assessment
}

\author{
Aminreza Neshat • Biswajeet Pradhan
}

Received: 22 April 2014/Accepted: 2 November 2014/Published online: 9 November 2014

(C) Springer Science+Business Media Dordrecht 2014

\begin{abstract}
Groundwater management can be effectively implemented by mapping groundwater contamination. Intense agricultural activities and land overexploitation have resulted in groundwater contamination, which is becoming a critical issue, specifically in areas where fertilizers are extensively used on large plantations. The goal of this study was to develop an integrated DRASTIC model with a frequency ratio (FR) as a novel approach. Two new hybrid methods namely single-parameter sensitivity analysis (SPSA) and an analytical hierarchy process (AHP) are also implemented for adjusting feature weights to local settings. The FR is used for DRASTIC model rates, whereas both SPSA and AHP are used for DRASTIC weights. The FR-DRASTIC, FR-SPSA and FR-AHP methods are developed; nitrate samples from the same month in different years are used for analysis and correlation (May 2010 and May 2012). The first nitrate samples are interpolated using the Kriging approach. The Kerman plain is used as an example, which is located in southeastern part of Iran. Additionally, the new methods are employed in the study area to compare with each other and the original DRASTIC model. The validation results exhibited that using FR approach improved the correlation between vulnerability index and nitrate concentrations compared with original DRASTIC vulnerability correlation which was 0.37 . The results indicated that the new hybrid methods exhibited higher correlation 0.75 in the FR-DRASTIC model. Correlations of the FR-SPSA and FR-AHP approaches were 0.77 and 0.80 . Hence, the new hybrid methods are more effective and provide reasonably good results. Furthermore, quantitative measures of vulnerability offer an excellent opportunity to effectively prevent as well as reduce contamination.
\end{abstract}

Keywords Groundwater contamination · Nitrate - GIS · Frequency ratio · Kerman plain · Iran

\footnotetext{
A. Neshat $(\bowtie) \cdot$ B. Pradhan $(\bowtie)$

Department of Civil Engineering, Geospatial Information Science Research Center (GISRC), Faculty of Engineering, University Putra Malaysia, 43400 Serdang, Selangor, Malaysia e-mail: neshat.aminreza@gmail.com

B. Pradhan

e-mail: biswajeet24@gmail.com; biswajeet@lycos.com
} 


\section{Introduction}

Groundwater pollution is becoming a prevalent issue, particularly in agricultural lands where fertilizers are largely used on plantations. Because groundwater pollution is imperceptible and long-term effects are costly, groundwater contamination prevention is indispensable for efficient groundwater resource management. Evaluating groundwater vulnerability has been recently identified as an important method for environmental management (Yu et al. 2010). Groundwater vulnerability is relative, dimensionless and non-measurable feature which relies on geological and hydrogeological aquifer characteristics (Antonakos and Lambrakis 2007; Fijani et al. 2013).

Agriculture is the main activity in majority of the lands; therefore, fertilizers are extensively used in this area. The application of alternative methods and environmental management can be presented through the DRASTIC model. The vulnerability results obtained through this model are considered unreliable because the area specifics are not fulfilled due to the selected features as well as the adopted feature ratings and weights used by the model. Therefore, the DRASTIC model is an easy target for criticism. Numerous studies have suggested modifications in the DRASTIC-based algorithms to develop this method further (Afshar et al. 2007; Antonakos and Lambrakis 2007; Carvalho and Pacheco 2009; Pacheco and Sanches Fernandes 2013).

Several intrinsic vulnerability parameters, e.g., depth to groundwater, net recharge and soil media, have been altered due to increased human activities. Recently, nitrate has been used as a good indicator for groundwater contamination sources and risk assessment (Stigter et al. 2008; Farjad et al. 2012; Neshat et al. 2013; Li and Merchant 2013; Chen et al. 2013; Boy-Roura et al. 2013; Chica-Olmo et al. 2014). Various approaches have been developed to evaluate groundwater vulnerability (Masetti et al. 2009). Vulnerability assessments must be objective, scientific and based on accurate evidence (Mohammadi et al. 2009). The available techniques for the evaluation of groundwater vulnerability include (1) overlay index methods (Aller et al. 1985), (2) process-based models (Neukum and Azzam 2009) and (3) statistical methods (Masetti et al. 2009). The overlay index methods include a set of subjective ratings and a weight-allocating scheme. The DRASTIC method is the most commonly used overlay index technique to evaluate intrinsic vulnerability (Aller et al. 1987). Process-based methods simulate contaminant subsurface flow and transport (Kauffman and Chapelle 2010). Moreover, statistical methods range from simple descriptive statistics to more complex regression analyses that synthesize explanatory variables to identify the importance of affected parameters on groundwater vulnerability. To produce scientifically strong information for water resource managers, the process-based and statistical methods are preferred over the index overlying methods, which rely on professional judgment (Focazio et al. 2008). Although groundwater vulnerability models generally include similar parameters, the models apply different data integration approaches (Li and Merchant 2013). The DRASTIC method is relatively easy to implement. However, the method has been indicated to produce varied results when applied to a single region (Gogu et al. 2003; Frind and Martin 2004). Therefore, statistical models allow researchers to appropriately choose parameters with respect to the specific study area and to immediately investigate the spatial distribution effects of contamination (Masetti et al. 2009).

A method such as probabilistic frequency ratio (FR) approach has not been applied for groundwater vulnerability assessment which is different in its application compared with other studies. The FR was used in landslide susceptibility assessment (Pradhan et al. 2010; Yalcin et al. 2011; Pradhan and Lee 2010a; Nourani et al. 2014; Demir et al. 2013; 
Mohammady et al. 2012), groundwater potential mapping (Oh et al. 2011; Ozdemir 2011; Nampak et al. 2014) and other environmental disciplines. Also, a GIS-based combination of analytical hierarchy process (AHP) with DRASTIC model was applied as an efficient tool for groundwater vulnerability evaluation (Neshat et al. 2014a). Saaty (1980) proposed the process of AHP, which is a multi-criteria decision-making (MCDM) technique. AHP has been generally used in solving many complicated decision-making problems (Anane et al. 2012; Althuwaynee et al. 2014; Pourghasemi et al. 2012; Feizizadeh and Blaschke 2013; Roodposhti et al. 2014; Demir et al. 2013; Stefanidis and Stathis 2013; Neshat et al. 2014a; Youssef et al. 2011). Afterward, the single-parameter sensitivity analysis (SPSA) offers useful information on the effect of weighting values allocated to each parameter and supports the analyst in judging the importance of subjectivity (Gogu et al. 2003; Babiker et al. 2005; Huan et al. 2012). Identification and qualitative comparison of sensitivity analysis methods that have been used across various disciplines (Christopher Frey and Patil 2002).

In this study, a probabilistic-based statistical model, i.e., the FR, is an original idea applied as a pioneering approach to optimize the DRASTIC model rates. First, the FR for DRASTIC model rates is combined with the original DRASTIC model weights. Second, two new hybrid methods are applied which are based on integrating the FR rates with SPSA and AHP as weights. Then, the derived outcomes are compared. The correlation between the predicted and actual contamination occurrences (nitrate concentration), their complexity and their data requirements are discussed. Nitrates are chosen to indicate contamination because they are the primary human-supplied contaminant in the environment of the study area and have been suggested as an explanatory index for the groundwater quality decline (USEPA 1996). Moreover, in many studies, nitrate was applied for modification the rate of DRASTIC model with surveys on the real quality of water from wells (Rupert 2001; Panagopoulos et al. 2006; Antonakos and Lambrakis 2007; Javadi et al. 2011; Mishima et al. 2011; Neshat et al. 2014a, b).

\section{Study area and data used}

The study area is located in the Kerman plain (Fig. 1), which is an arid and semiarid region located in southeastern Iran and encompasses approximately $978 \mathrm{~km}^{2}$. The altitude ranges from 1,633 to $1,980 \mathrm{~m}$ above sea level. The average annual rainfall in 2011 was $108.3 \mathrm{~mm}$. Moreover, the climate is characterized by hot and dry summers, relatively rainy winters, and short spring and autumn seasons. Within a typical water year, nearly 2 months are glacially related, i.e., January and February. According to Water organizations of Kerman during recent years, this phenomenon has decreased due to climate change. Because pistachio is the primary agricultural product in the study area, groundwater is extremely essential for the economic survival of this region.

The geology of Kerman plain consists of Cretaceous and Eocene conglomerates (PC), intrusive rocks (gp), Eocene and Neogene volcanism, and Neogene or younger sediments. In the study area, the aquifer media is primarily composed of marl and conglomerate rocks in the south and a small area in the northwest. Fine-medium sand is elongated across the north and northeast. Deposits of silt and clay are located in the central region. Moreover, the immense sand deposits with a very low fine-grained material ratio are considered gravel and sand. Glacial till was introduced by Aller et al. (1987) and Rahman (2008), which represents a mixture of gravel, sand, silt and clay. The vadose zone and soil media perform important roles in groundwater pollution vulnerability (Huan et al. 2012). The soil 


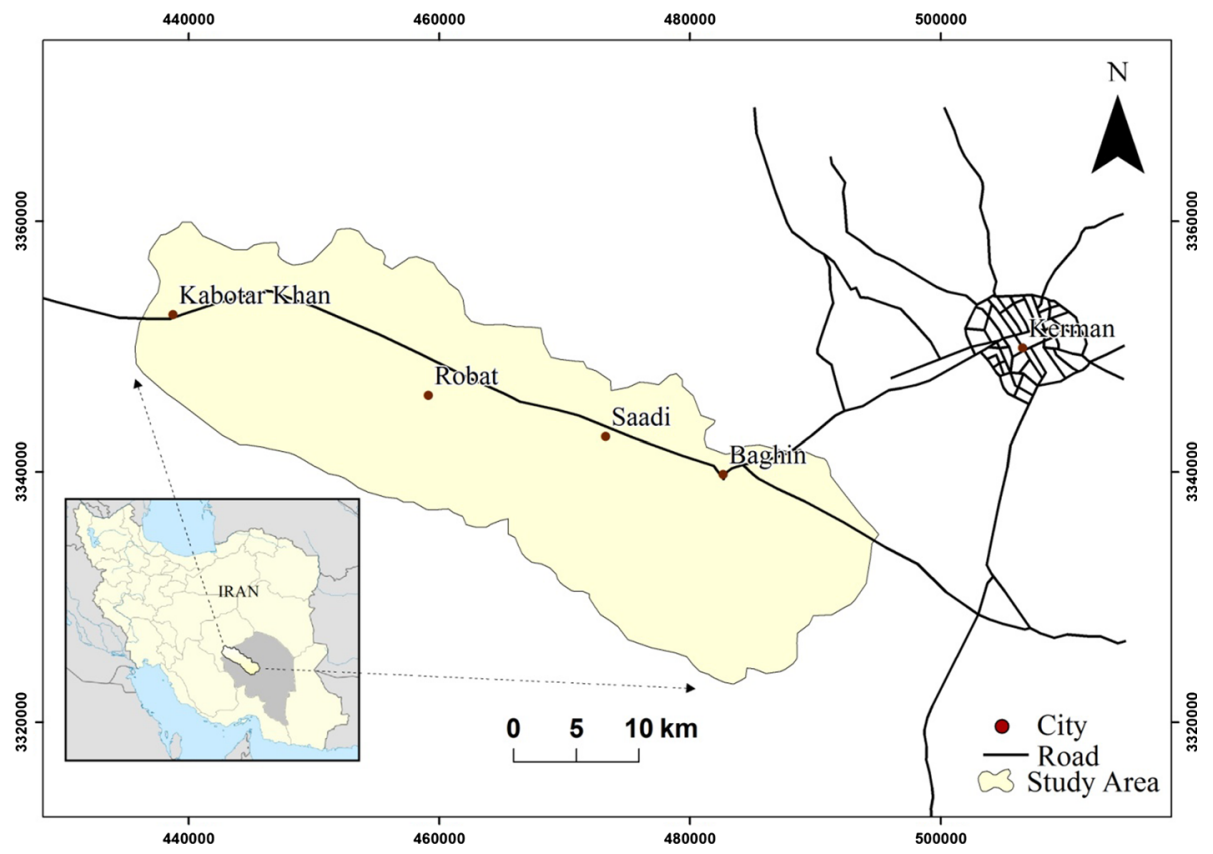

Fig. 1 Location map

type in the study area is primarily clay loam, gravel, non-shrinking loam and non-aggregated clay, sand, sandy loam and silty loam. The available soil media layer represents a sand section with high permeability located to the north and south in the study area.

The depth from the surface to the groundwater table in the Kerman plain typically varies from $15 \mathrm{~m}$ to more than $30 \mathrm{~m}$. Therefore, the depths were classified into three classes (15-23, 23-30 and $>30 \mathrm{~m})$; most values were placed in the third class. Given that the study area is located in an arid or semiarid region, two classes less than $30 \mathrm{~m}$ indicate irrigation return flow. Rainfall infiltration, irrigation return flow and absorption wells are the primary groundwater recharge sources in the area. The total net recharge in the study area is 186.06 million cubic meters per year $\left(\mathrm{Mm}^{3} / \mathrm{y}\right)$.

The topography was derived from a digital elevation model using a topographic map $(1: 25,000)$. The slopes typically range from 0 to 2 and $2-6 \%$. The vadose zone types primarily include silt-clay and sand-gravel in the west. A small region situated in the northeast exclusively contains gravel and sand.

The maximum electrical conductivity (EC) in the study area is $3,880 \mu$ mhos per centimeter $(\mu \mathrm{S}$; the average $\mathrm{EC}$ is $2,700 \mu \mathrm{S}$. Moreover, the minimum EC is $1,100 \mu \mathrm{S}$. In addition, the southeastern regions contain the maximum EC. Available nitrate measurement sampling was collected during the period 2010-2012 from 27 agricultural wells. The model was calibrated with the first and second nitrate samples collected in May 2010 and May 2012, respectively. Nitrate samples in May 2010 used to calibrate the rates of DRASTIC due to applying FR and nitrate samples in May 2012 used for correlation coefficient. These samples were used to create a relationship between nitrate concentration and groundwater vulnerability. All of the data that include seven hydrogeological factors and nitrate samples are explained in Table 1, which are obtained from different sources. 


\section{Methodology}

\subsection{DRASTIC model}

The DRASTIC model (Aller et al. 1987) is the most popular subjective rating method to evaluate intrinsic groundwater vulnerability. The intrinsic vulnerability is independent of specific contamination and is considered according to the geological, hydrogeological and hydrological characteristics of the area (Zwahlen 2004). The seven hydrological layers designated by Aller et al. (1987) were denoted by the acronym "DRASTIC," which assigned a rating from 1 to 10 and a weighting from 1 to 5 to each parameter. The model then used seven parameters to estimate the vulnerability index: depth to water, net recharge, aquifer media, soil media, topography, vadose zone impact and hydraulic conductivity. The original DRASTIC index was calculated by applying a linear combination of all parameters:

VulnerabilityIndex $(\mathrm{VI})=D_{\mathrm{R}} D_{\mathrm{W}}+R_{\mathrm{R}} R_{\mathrm{W}}+A_{\mathrm{R}} A_{\mathrm{W}}+S_{\mathrm{R}} S_{\mathrm{W}}+T_{\mathrm{R}} T_{\mathrm{W}}+I_{\mathrm{R}} I_{\mathrm{W}}+C_{\mathrm{R}} C_{\mathrm{W}}$

where the vulnerability index (VI) represents the DRASTIC result and the subscripts $W$ and $R$ represent the importance of weight and rate, respectively, for each parameter. A model deficiency is the innate subjectivity in assigning the rating value and relative weighting (Saidi et al. 2011). However, its preference cannot be disregarded. The intrinsic vulnerability using the DRASTIC method compared with other models can be assessed by various hydrogeological parameter types and requires a moderately small volume of data (Wang et al. 2012).

\subsection{Nitrate concentration assessment}

Nitrate concentration was chosen as the initial contamination in the Kerman plain because of the intensive agricultural activities and widespread use of fertilizer in this region. Nitrate normally penetrates the surface and proceeds into underground water. Sampling and analysis were carried out on 27 agricultural wells.

According to Panagopoulos et al. (2006), Antonakos and Lambrakis (2007) and Neshat et al. (2013), an area should comply with the following three conditions for optimization of the rates of DRASTIC model based on the nitrate concentration: (1) the mean surface nitrate concentration should be an effect of the agricultural activities; (2) the distribution area should be relatively uniform; and (3) nitrate leaching occurs because of surface recharge over long periods. Based on these conditions, the nitrate samples in 2010 are interpolated using the ordinary Kriging interpolation algorithm to obtain nitrate concentrations in each factor's range in the area (Fig. 2). It is also among the most common interpolating methods in agriculture practices (Mishra 2009) which used as a geostatistical estimation method in the class of the minimum error variance estimation (Baalousha 2010; Mendes and Ribeiro 2010). This interpolation technique is implemented because the goal is to optimize the rates of DRASTIC model, which has not been applied thus far. In quantitative studies, the number of examined objects, such as wells, is countable or visible. However, nitrate can be distributed anywhere underground and may not have existed in wells. 
Table 1 Data sources used for preparation of DRASTIC parameters

\begin{tabular}{ll}
\hline Data type & Sources \\
\hline 1. Hydrogeological data & Meteorological organization of Kerman \\
2. Geology map & Geological survey of IRAN \\
3. Soil map & Soil and water research institute of Kerman \\
4. Topography & Water organizations of Kerman \\
5. Wells & Water organizations of Kerman \\
6. Hydraulic conductivity & Water organization of Kerman \\
7. Geological profile & Water organization of Kerman \\
8. Groundwater balance of Kerman & Water organization of Kerman \\
plain & Two times sampling based on surveys in the study area using GPS \\
9. Sample wells & technique \\
\hline
\end{tabular}

Using the Kriging variance of estimate is independent of actual measurements from the field, which is the best linear unbiased estimator of an unknown field. The ordinary Kriging interpolation equation is as follows:

$$
Z *\left(x_{0}\right)=\sum_{i=1}^{n} n \lambda_{i} Z\left(x_{i}\right)
$$

where $Z^{*}\left(x_{0}\right)$ is the estimated value, $n$ is the number of points, $Z\left(x_{i}\right)$ is the measured value at point $x_{i}$ and $\lambda_{i}$ is the Kriging weight.

\subsection{Frequency ratio (FR)}

Frequency ratio approach as a bivariate statistical analysis provides a new framework to assess groundwater vulnerability through calibration the rates of DRASTIC parameter based on the spatial distribution of nitrate samples and hydrogeological factors.

To evaluate groundwater vulnerability in the study area, it is pertinent to discuss the circumstances that can cause groundwater contamination. The FR model is based on the observed relationships between the distribution of nitrate samples and each of the seven DRASTIC layers to determine the correlation between nitrate samples and DRASTIC parameters. By using the FR model, the spatial relationships between the nitrate samples and parameters, which contribute to the groundwater vulnerability map, can be ascertained. The FR was computed from the analysis of nitrate association and attributed factors. Therefore, the FRs of each factor type or range were calculated from their relationships with the nitrate samples. The processes can be understood as follows:

$$
\mathrm{FR}=(A / B) /(C / D)=E / F
$$

where $A$ is the area of a class or range for each DRASTIC parameters; $B$ is the total area of each parameter; $C$ is the total number of nitrates occurrence in the class of each parameter; $D$ is the number of the total nitrates in the study area; $E$ is the percentage of nitrates in the class of each parameter; $F$ is the percentage of area in the class for each parameter.

In defining the FR, the nitrate concentration area ratio was computed in the range of each DRASTIC layer factor; the area ratio for the range of each factor relative to the total area was calculated. Then, the probability for each parameter range was computed by dividing the nitrate concentration ratio by the area ratio; a value of 1 is an average ratio. If 
the ratio is $>1$, a higher correlation between the factor range and nitrate concentration is indicated. Moreover, if the ratio is $<1$, a lower correlation is expected (Pradhan and Lee 2010b; Yalchin et al. 2011; Umar et al. 2014)

\subsection{Analytical hierarchy processes (AHP)}

The AHP method proposed by Saaty (1980) provides a readily applied approach to solve complex problems, which has been environmentally used in site selection and land allocation. The method is a multi-criteria decision-making method that allows the user to obtain a priority scale that is derived from a set of alternatives. To apply this method, it is essential to decompose a complex unstructured subject into its constituent factors, organize these factors in a hierarchical order, assign numerical values to subjective judgments on the relative importance of each factor and combine the judgments to decide the allocated priorities for these factors (Saaty and Vargas 2001). Constructing a set of pairwise comparison matrices (PCMs) is the most important component of the AHP method, which permits the comparison between various criteria. In this study, the PCM was completed through 13 expert judgments.

For the AHP procedure, the first criterion weight was multiplied by the first column of the main PCM and used to define the weighted sum vector. Subsequently, the other criteria were individually multiplied by their respective columns in the original matrix. To obtain a final value, the derived values were added over the rows. The weighted sum vector was divided by the criterion weights to determine the consistency index.

The consistency index was calculated by

$$
\mathrm{CI}=\left(\lambda_{\max }-n\right) /(n-1)
$$

where $\lambda_{\max }$ is the maximum consistency vector and $n$ is the criteria number. Then, the consistency ratio, which defines the consistency of each matrix, was calculated by

$$
\mathrm{CR}=\mathrm{CI} / \mathrm{RI}
$$

where $\mathrm{CR}$ is the ratio of the consistency index (CI) and random index (RI). As a general rule, $\mathrm{CR} \leq 0.1$ should be preserved for the matrix to be consistent.

The consistency ratio (CR) was calculated for all models in which the AHP was applied. If the CR is $>0.1$, the models were automatically neglected. This process was applied to compute the weights of all DRASTIC parameters by modifying the initial weights of factors for determining the vulnerability.

\subsection{Single-parameter sensitivity analysis (SPSA)}

The single-parameter sensitivity is introduced by Napolitano and Fabbri (1996). The SPSA offers useful information on the effect of weighting values allocated to each parameter and supports the analyst in judging the importance of subjectivity (Gogu et al. 2003; Babiker et al. 2005; Huan et al. 2012; Li and Merchant 2013). The most effective parameters are defined by comparing the theoretical weights with the SPSA. The effective weight was computed as

$$
W=\left(\left(P_{\mathrm{r}} \times P_{\mathrm{w}}\right) \div V\right) \times 100
$$

where $W$ is the effective weight of each parameter and $V$ is the overall vulnerability index. Moreover, $P_{\mathrm{r}}$ and $P_{\mathrm{w}}$ are the rating value and weight of each parameter, respectively. 


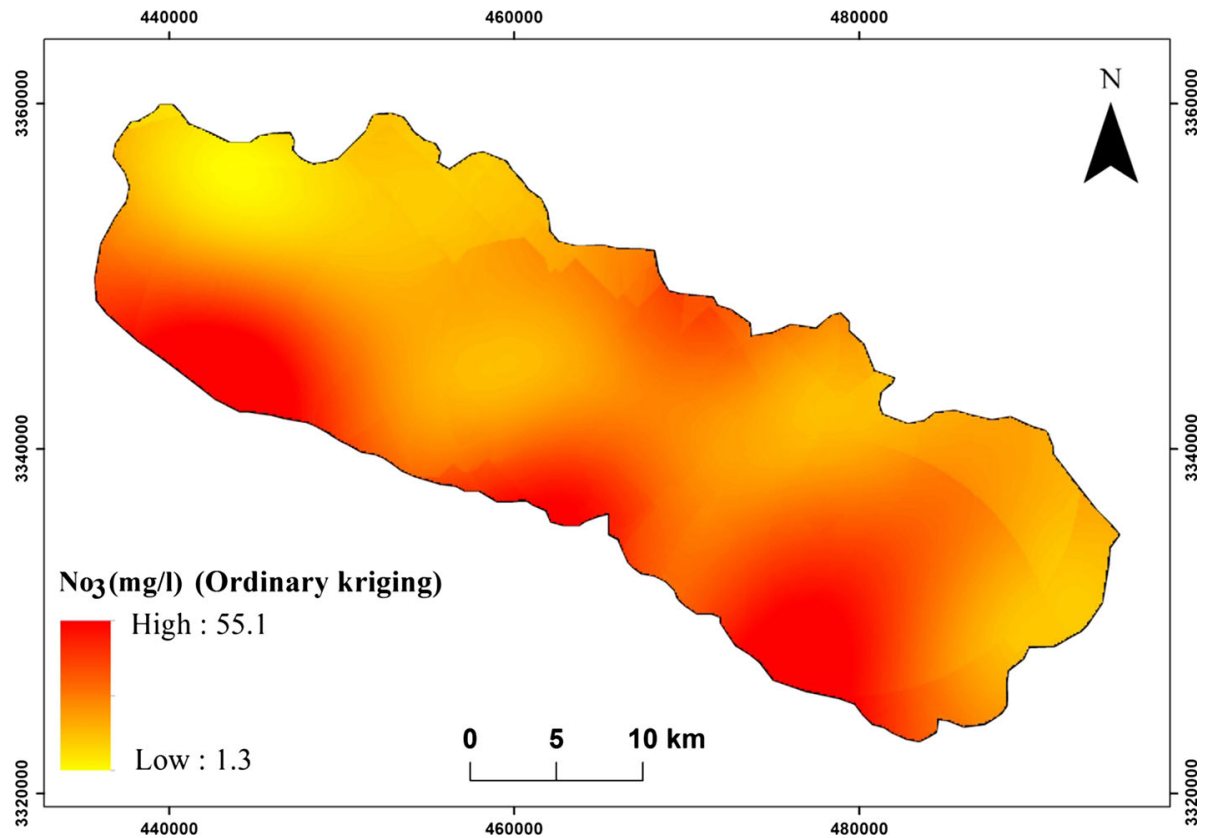

Fig. 2 Ordinary Kriging interpolation using nitrate sample (May 2010)

\subsection{Optimization of the DRASTIC model to groundwater contamination vulnerability}

In this study, groundwater vulnerability maps were prepared using three different procedures in a GIS-based approach. The original DRASTIC model weights and three other approaches to optimize the DRASTIC model rates and weights were used, including the FR, AHP and SPSA approaches. These methods were integrated and used to develop the FR-DRASTIC model and two new hybrid methods, i.e., FR-AHP and FR-SPSA. The area and percentage distribution of the vulnerable classes in the study area were determined using the three different maps. The vulnerability maps were classified into five vulnerability classes: very low, low, moderate, high and very high. To validate and compare the derived results between groundwater vulnerability and nitrate concentration, the Pearson's correlation was determined.

\subsubsection{Revision of the rates using frequency ratio model}

Increasing the rating scale validity is important for producing accurate groundwater vulnerability assessment results (Baalousha 2010; Assaf and Saadah 2009). In this method, the highest DRASTIC rate in the study area was given a higher probability, which was derived from the FR; a relation was applied to obtain the other DRASTIC rates. By optimizing the DRASTIC model rates based on the FR approach compared with the Wilcoxon modification, which is one of the most effective rating scale revisions (Panagopoulos et al. 2006; Antonakos and Lambrakis 2007), indicates that regions with no data have been assigned a value due to the interpolation of nitrate samples. Therefore, nitrate is available in all DRASTIC layer ranges. 


\subsubsection{Revision of the weights}

The index weights show their relative necessity. The DRASTIC model weights for the study area may contain some ambiguity because the same index has different impacts on groundwater vulnerability in various regions (Huan et al. 2012). In this study, the weights are reassigned using revised weights. The revised weight for each DRASTIC parameter is determined by applying two methods, i.e., AHP and SPSA. These methods are efficient for revision of DRASTIC weights due to considering local hydrological setting and effective weights of each parameter. The procedure for revising the weights using the aforementioned methods integrates the FR approach and generates new modification of vulnerability maps.

\subsection{Validation of groundwater vulnerability and analysis nitrate samples}

Various validation methods exist in the literature, including analyzing the hydrographs and chemographs, isotopic chemistry, using an artificial tracer and using analytical and numerical models (Zwahlen 2004; Wang et al. 2012). Many other studies have implemented the same validation techniques for, e.g., groundwater nitrate concentration analysis, groundwater quality analysis, groundwater flow models, statistical methods and sensitivity analysis (Babiker et al. 2005; Panagopoulos et al. 2006; Nobre et al. 2007; Neshat et al. 2013; Boughriba et al. 2010; Chitsazan and Akhtari 2009; Saidi et al. 2010; Saidi et al. 2011; Wang et al. 2012; Huan et al. 2012). In this study, the method efficiency was validated using nitrate concentration distributions. The nitrate concentration in the study area was selected as the primary contamination parameter. Nitrate concentrations were sampled at 27 agricultural wells. The samples were collected in May from 2 years (2010 and 2012). Although groundwater vulnerability is relative and not absolute, analyzing nitrate concentrations or nitrate samples from the same month in each year reduces error in the Pearson's correlation factor. Here, two samples from the first and last study years were used because they better address the purpose of this investigation. The samples from 2010 and 2012 were analyzed and used to obtain correlations, respectively. Then, the samples derived from 2012 normalized which is more reliable and closer to the fact of study area are selected for correlation.

\section{Results and discussion}

\subsection{Intrinsic vulnerability map}

In this study, the original groundwater vulnerability map was determined and nitrate samples were compared. The intrinsic vulnerability map of the Kerman Plain (Fig. 3) was produced by integrating the seven layers of the DRASTIC method according to the weights and rates compiled by Aller et al. (1987). The vulnerability index was divided into five classes ranging from very low to very high. The southeastern and northern parts of the plain exhibit the highest vulnerability, demonstrating that these regions are most susceptible to contamination. In the central area, the vulnerability decreases from east to west. The DRASTIC-derived results indicate that $50.09 \%$ of the total study area is in the very high and high classes. Moreover, $30.81 \%$ of the area is moderately vulnerable; less than $20 \%$ of the study area is allocated to the low and very low contaminant vulnerability classes. The data analysis for 2011 indicates that the Pearson's correlation factor derived 
from the DRASTIC model is $R=0.44$ (Neshat et al. 2013). The correlation decreases to $R=0.37$ by using the nitrate samples from 2012. This reduction in correlation is due to increased fertilizer usage for agricultural activity in the Kerman plain, representing the importance of agricultural productivity in the area, which deteriorates the groundwater quality. The study area is located in an arid and semiarid region; clearly, groundwater is the only water source for agricultural activity and drinking water.

\subsection{Application of newly developed methods}

The new vulnerability index was calculated according to Eq. (7) (below), and the rates were modified using the FR approach and original DRASTIC model weights:

$$
\begin{aligned}
\text { FR-DRASTIC }=D_{(\text {modfr })} D_{\mathrm{W}}+ & R_{(\text {modfr })} R_{\mathrm{W}}+A_{(\text {modfr })} A_{\mathrm{W}}+S_{(\text {modfr })} S_{\mathrm{W}} \\
& +T_{(\text {modfr })} T_{\mathrm{W}}+I_{(\text {modfr })} I_{\mathrm{W}}+C_{(\text {modfr })} C_{\mathrm{W}}
\end{aligned}
$$

where mod fr expresses the modified rates obtained from the FR method multiplied by the original DRASTIC weights.

Table 2 indicates the original and modified rating values for each DRASTIC layer class. Modified rating values were derived by interpolating the 27 nitrate concentration samples (Fig. 4). In order to optimizing the rates of DRASTIC parameter's range based on FR, the highest rate of DRASTIC of each factor's range in the study area was given to the highest FR value and the other rates of DRASTIC factor's ranges were calculated through proportion. In the case of water table factor, the DRASTIC rates range from 1 to 3 . As the highest rate of DRASTIC is 3, the highest FR value obtained 3 as well, while the modified rates of study area based on FR value in each class of net recharge indicates that the highest rate assigned to the lowest original DRASTIC rate which obtained 6 and the rest of weighting rates were modified linearly. Also the lowest rate belongs to the highest DRASTIC rate which changed to 3.7. For the aquifer media, the rates of each class were based on the study area permeability varies from 2 to 8 . According to the original DRASTIC rates, in the study area, gravel-sand has the highest rate but in the modified rate marlstone due to the higher FR value derived highest rate which is 8 . The minimum modified rate of DRASTIC obtained 1.2 which calculated proportionally and changed linearly.

The study area was split into seven discrete groups of soil media including clay loam, gravel, silty loam, loam, sandy loam, sand and none shrinking. The maximum of original and modified rate was allocated to gravel and sand due to their permeability. Also the rates of the other classes calculated accordingly based on FR value in each class. For topography parameter, five slope groups were determined based on Aller et al. (1987). The lower rates of original DRASTIC were assigned to the higher slopes continuously, but in the Kerman plain the rates have been changed according to the FR value in the area. The modified rate of DRASTIC for slope ranges from $12^{\circ}$ to $18^{\circ}$ has the highest rate due to the highest FR value and the lowest rate of FR value belongs to ranges between 0 and 2 degree in the study area with value of 4.1. The vadose zone plays a significant role in percolation of rainfall and surface water flow. Silt and clay, sand and gravel, and gravel and sand with silt and clay are the main classes of vadose zone parameter. As illustrated in Fig. 4, the modified rates of DRASTIC in the study area vary from 1.9 to 8 . Based on the FR value and relation between the factor's ranges, the lowest and highest rates were assigned to silt/ clay and marlstone shale, respectively. In the case of conductivity in the study area, the original DRASTIC rates range from 1 to 4 , but in the modified rates of DRASTIC, the 


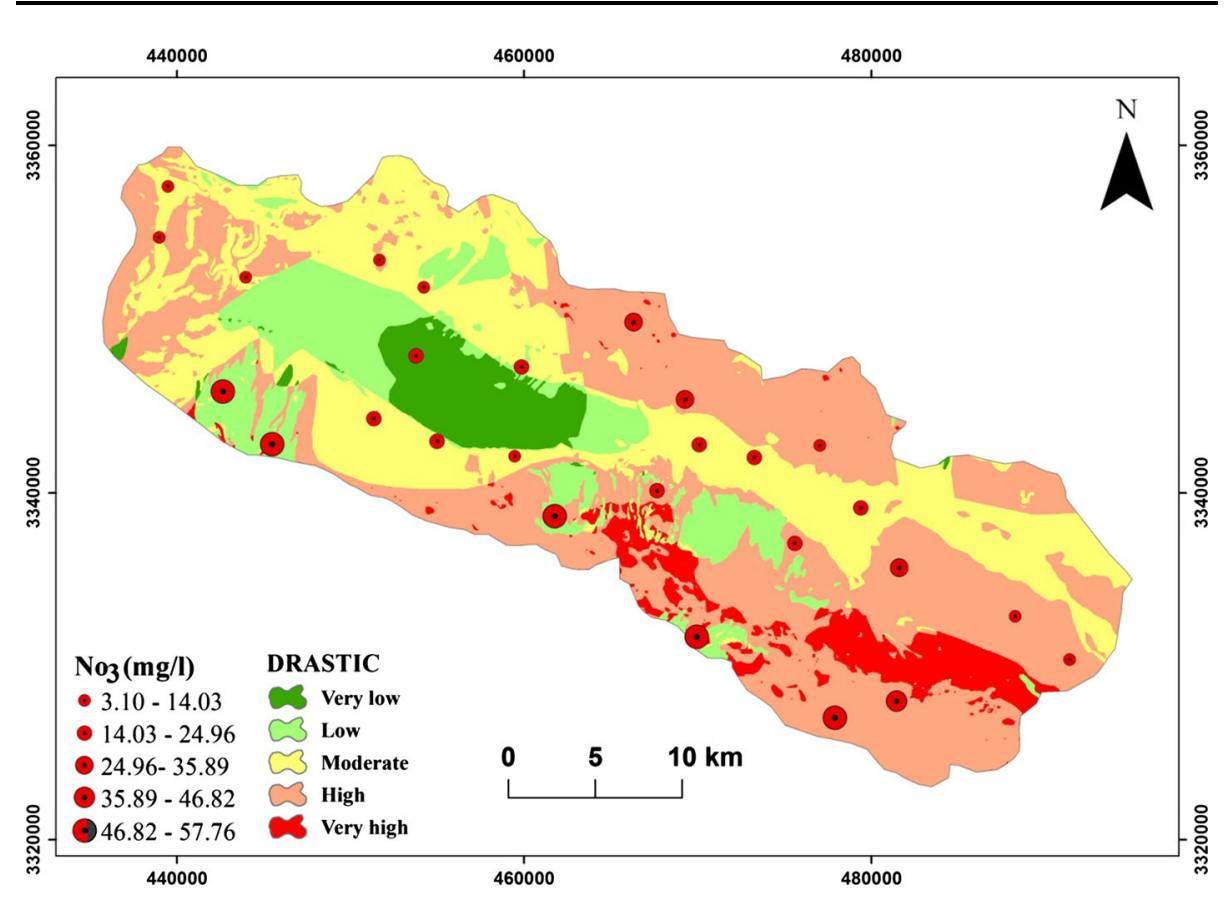

Fig. 3 Intrinsic vulnerability map and nitrate sample (May 2012)

lowest rate is 1.3 which was assigned to 4-12 class and the highest modified rate allocated to the lowest original DRASTIC rate.

In the new hybrid FR-DRASTIC method, the very high and high indexes correspond to high potential vulnerability areas. Figure 5 indicates that the areas with the highest vulnerability are located in a small northern region and the southeast and southwest Kerman plain. The western and northeastern areas have lower contamination vulnerabilities; moderate vulnerability ranges were assigned to nearly half the area. Figure 8 illustrates that $36.15 \%$ of the Kerman plain exhibits lower vulnerability. Moreover, $15.44 \%$ of the study area exhibits high vulnerability.

In the second hybrid method, the weighting scores were optimized using SPSA. Table 3 shows the effective weights obtained from the SPSA. The lowest and highest effective weights from the depth to water and vadose zone impact were compared to the theoretical weights, respectively. Compared with the theoretical weights assigned by the DRASTIC model, the net recharge, aquifer media, soil media and slope had higher effective weights.

$$
\begin{array}{r}
\text { FR-SPSA }=D_{(\text {modfr })} \times 1.3+R_{(\text {modfr })} \times 4.7+A_{(\text {modfr })} \times 3.5+S_{(\text {modfr })} \times 3 \\
+T_{(\text {modfr })} \times 1.9+I_{(\text {modfr })} \times 6.9+C_{(\text {modfr })} \times 1.7
\end{array}
$$

As shown in Eq. (8), the modified rates are multiplied by weights derived from SPSA. The vulnerability area (Fig. 6) and its percentage illustrate that parts of the north, southwest and southeast have the higher vulnerability compared with the west and northwest, which exhibit lower vulnerability. Figure 8 shows that $29.43 \%$ of the total area is located in very high and high vulnerable areas. Moreover, $34.78 \%$ of the area is in moderate and $35.82 \%$ in low and very low classes. 


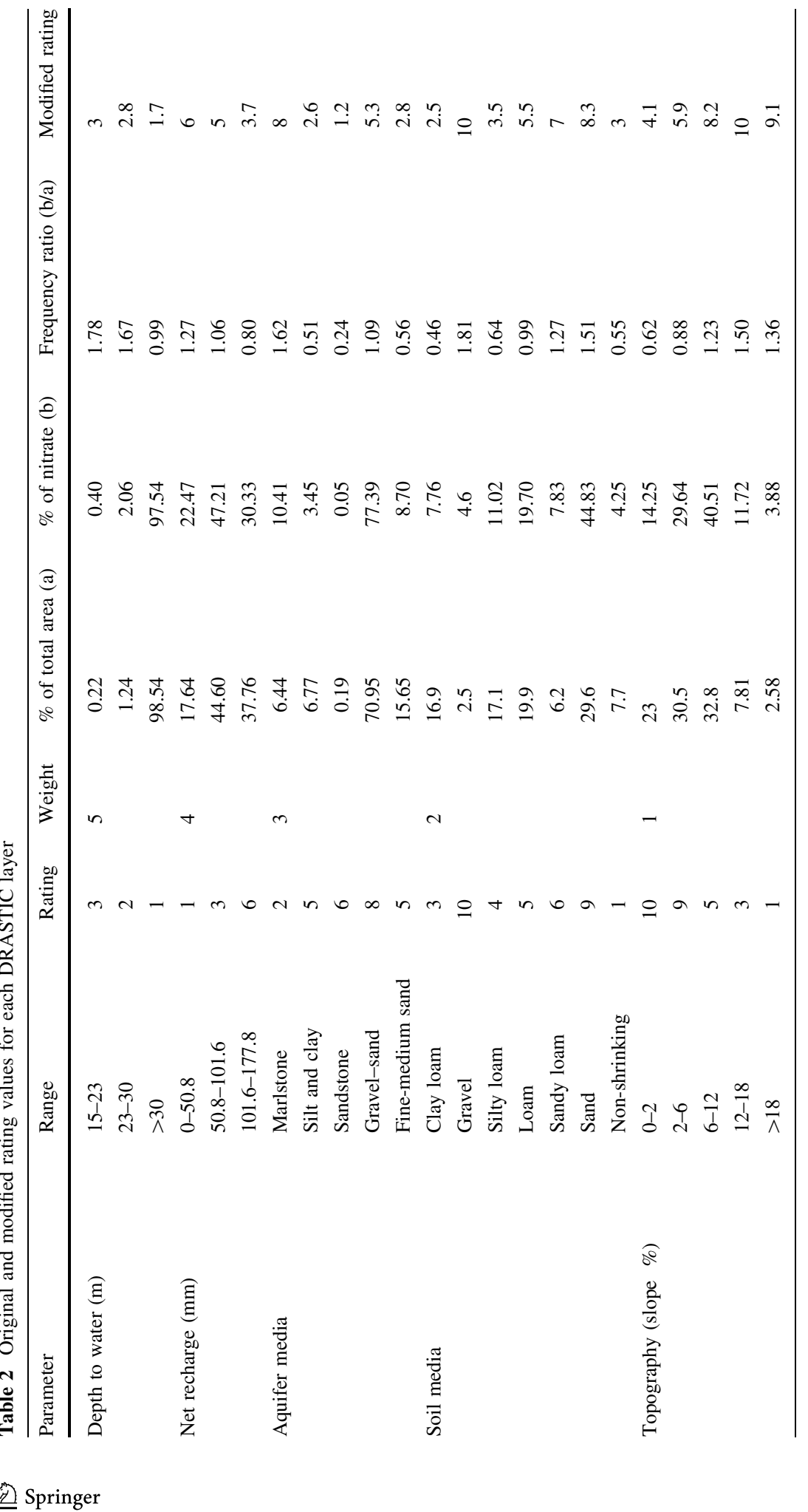




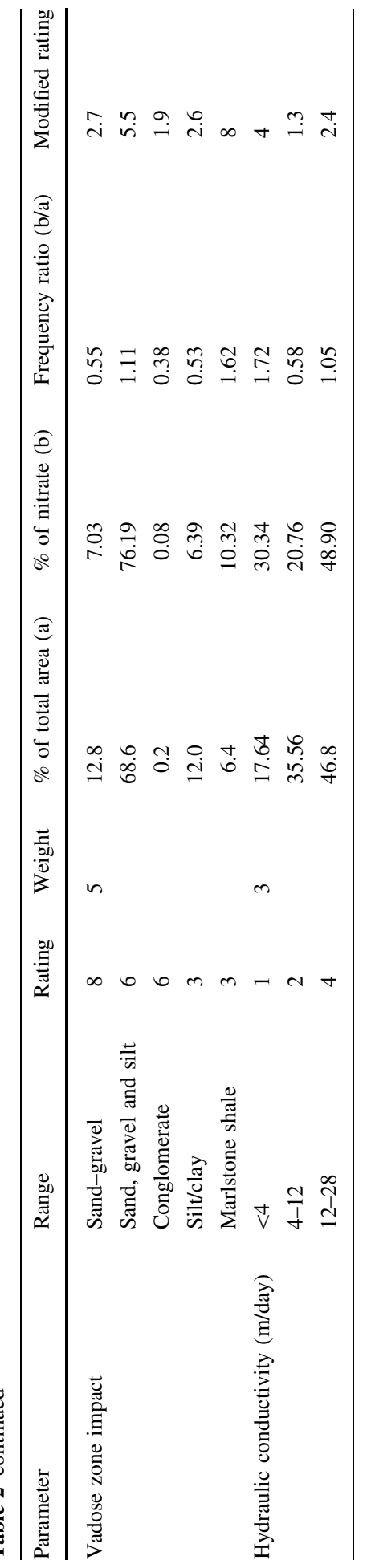



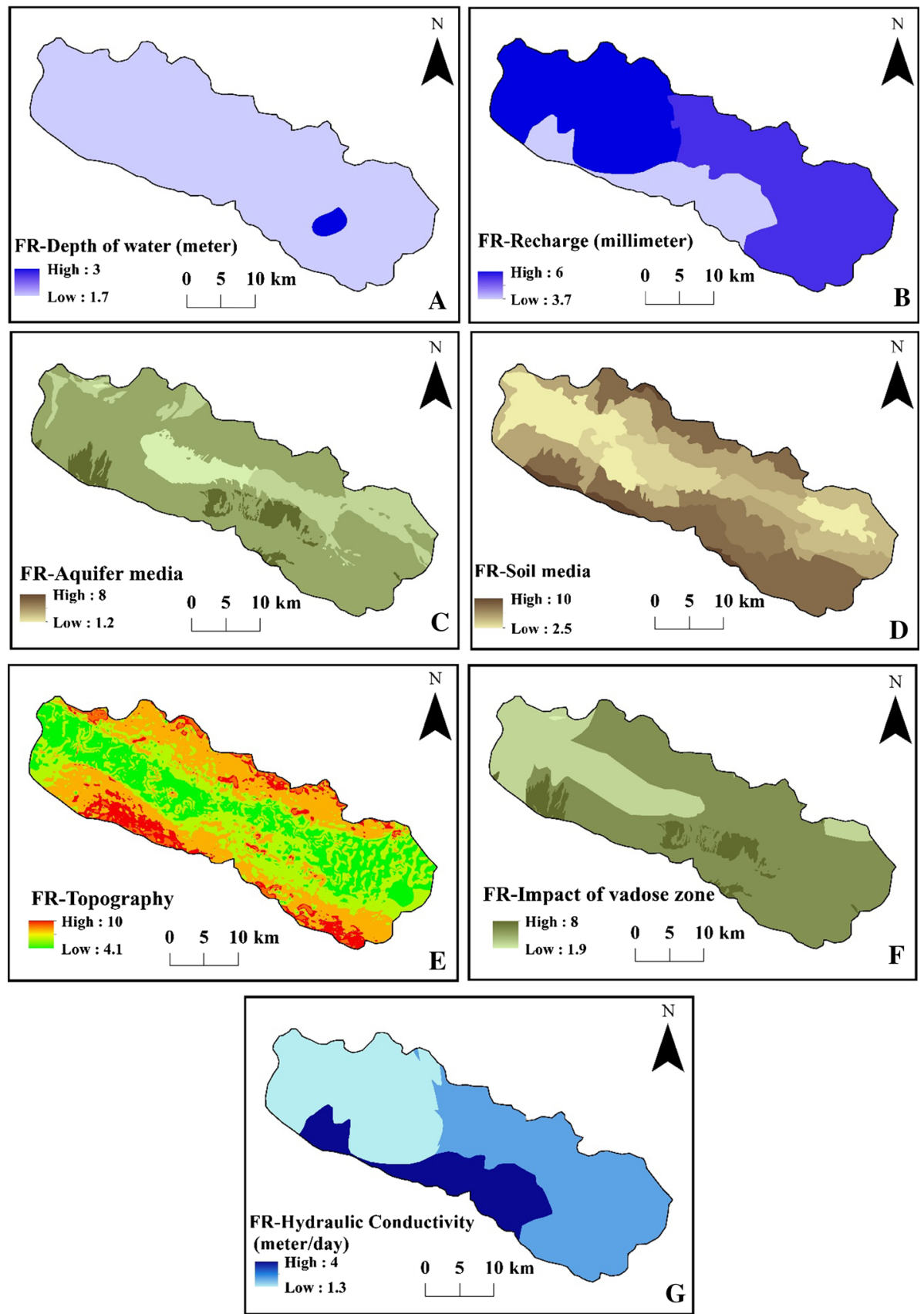

Fig. 4 Seven layers of modified DRASTIC rates using FR approach

In the last hybrid method, the effective weights of each DRASTIC parameter are compared with other parameters used in the AHP method. The pairwise comparison matrix was used for weighting the seven DRASTIC parameters, which was calculated by 


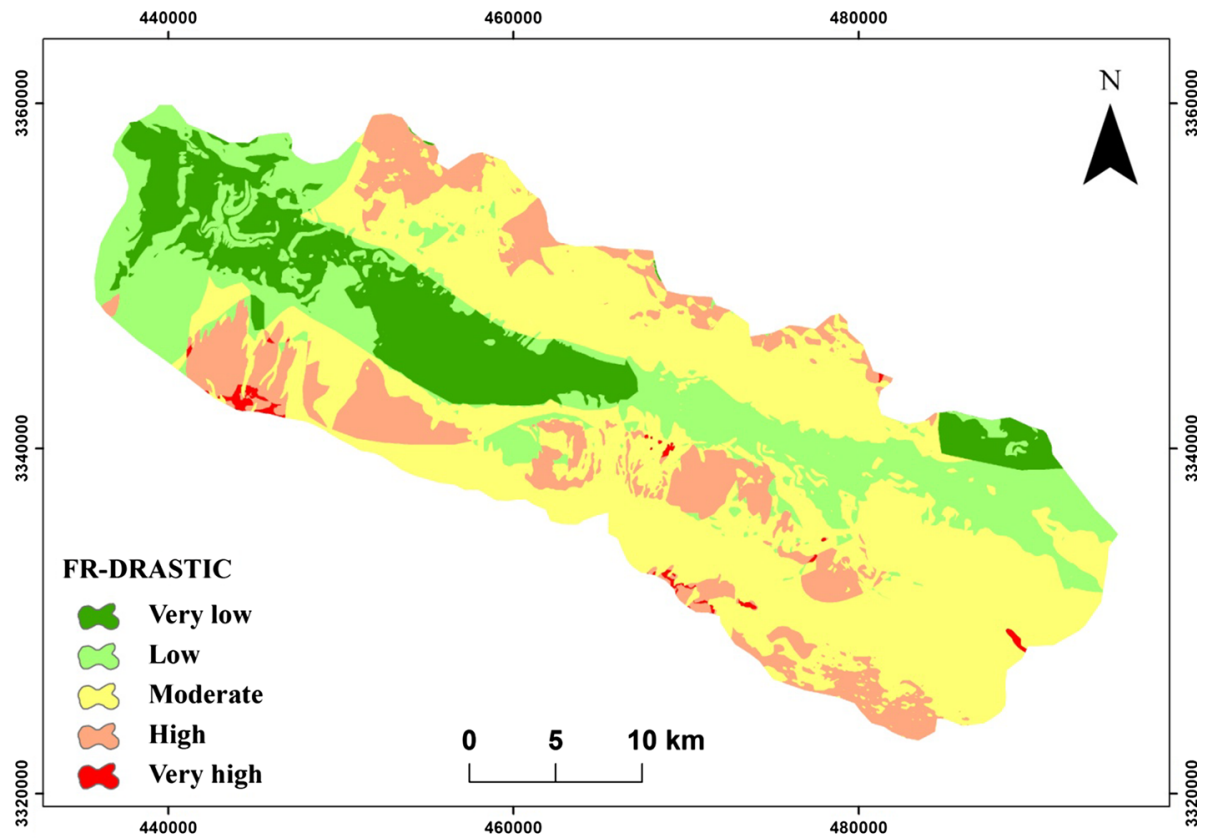

Fig. 5 FR-DRASTIC

Table 3 Statistics of single-parameter sensitivity analysis (SPSA)

\begin{tabular}{|c|c|c|c|c|c|c|c|}
\hline \multirow[t]{2}{*}{ Parameters } & \multirow{2}{*}{$\begin{array}{l}\text { Theoretical weight } \\
(\%)\end{array}$} & \multirow{2}{*}{$\begin{array}{l}\text { DRASTIC } \\
\text { weight }\end{array}$} & \multirow{2}{*}{$\begin{array}{l}\text { Modified } \\
\text { weight }\end{array}$} & \multicolumn{4}{|c|}{ Effective weight (\%) } \\
\hline & & & & Min & $\operatorname{Max}$ & Mean & SD \\
\hline Depth to water & 21.74 & 5 & 1.3 & 4.13 & 16.3 & 6.56 & 2.66 \\
\hline Net recharge & 17.39 & 4 & 4.7 & 3.36 & 42.1 & 20.43 & 10.6 \\
\hline Aquifer media & 13.04 & 3 & 3.5 & 3.29 & 28.23 & 15.21 & 5.64 \\
\hline Soil media & 8.7 & 2 & 3 & 4.39 & 25.97 & 12.53 & 4.57 \\
\hline Topography & 4.35 & 1 & 1.9 & 3.47 & 16.94 & 8.14 & 2.64 \\
\hline $\begin{array}{l}\text { Vadose zone } \\
\text { impact }\end{array}$ & 21.74 & 5 & 6.9 & 12.04 & 46.51 & 29.81 & 7.66 \\
\hline $\begin{array}{l}\text { Hydraulic } \\
\text { conductivity }\end{array}$ & 13.04 & 3 & 1.7 & 2.5 & 17.91 & 7.3 & 3.67 \\
\hline
\end{tabular}

multiplying the new rating coefficients. In this study, the best alternative weights derived from the AHP approach correspond to $\mathrm{CR}=0.075$. Table 4 shows the AHP-derived weights.

The DRASTIC layers including the statistically revised rates from both the FR and AHP weighting approaches were integrated to generate the FR-AHP model. The FR-AHP is calculated as 


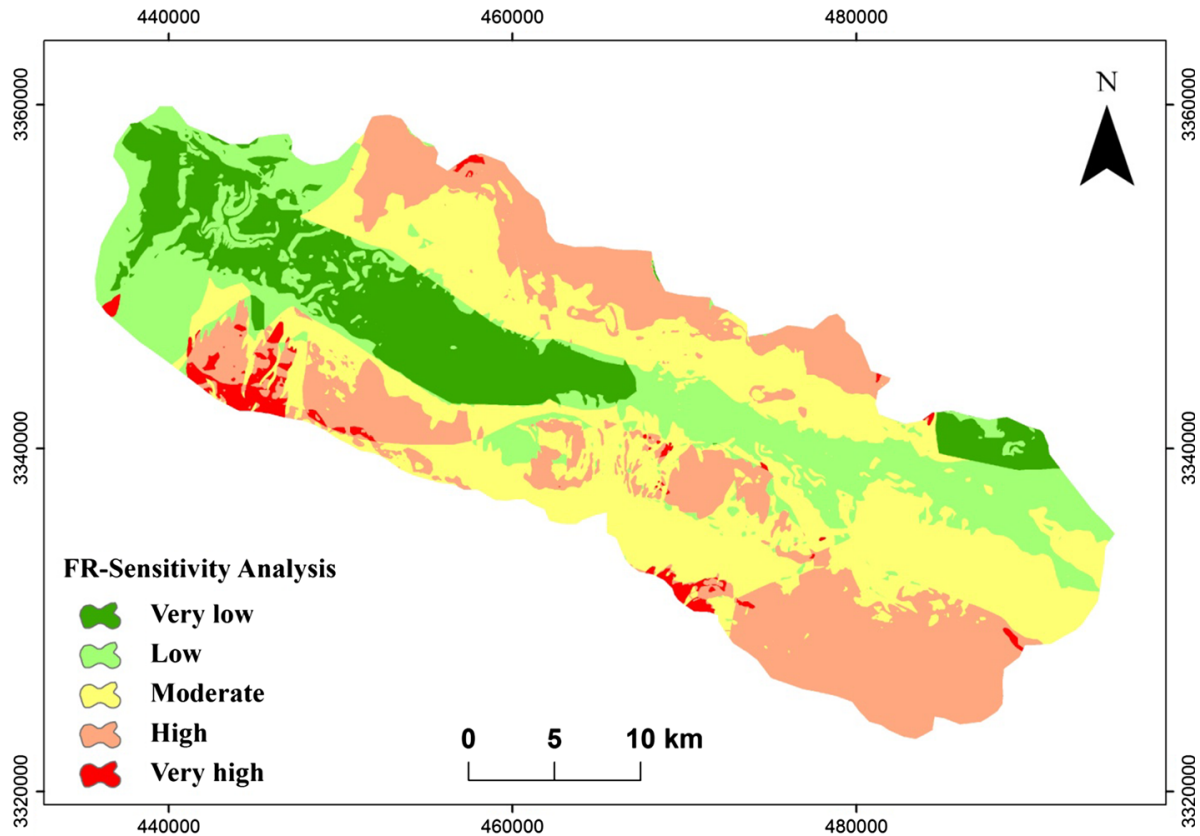

Fig. 6 FR-SPSA

Table 4 AHP-derived weights

\begin{tabular}{llllllll}
\hline Criteria & $\begin{array}{l}\text { Depth to } \\
\text { water }\end{array}$ & $\begin{array}{l}\text { Net } \\
\text { recharge }\end{array}$ & $\begin{array}{l}\text { Aquifer } \\
\text { media }\end{array}$ & $\begin{array}{l}\text { Soil } \\
\text { media }\end{array}$ & Topography & $\begin{array}{l}\text { Vadose zone } \\
\text { impact }\end{array}$ & $\begin{array}{l}\text { Hydraulic } \\
\text { conductivity }\end{array}$ \\
\hline $\begin{array}{c}\text { AHP } \\
\text { weight }\end{array}$ & 0.04 & 0.44 & 0.08 & 0.21 & 0.02 & 0.14 & 0.07 \\
\hline
\end{tabular}

$$
\begin{aligned}
\text { FR-AHP }=D_{(\text {modfr })} \times 0.04+ & R_{(\text {modfr })} \times 0.44+A_{(\text {modfr })} \times 0.08+S_{(\text {modfr })} \times 0.21 \\
+ & T_{(\text {modfr })} \times 0.02+I_{(\text {modfr })} \times 0.14+C_{(\text {modfr })} \times 0.07
\end{aligned}
$$

According to the obtained FR-AHP vulnerability map (Fig. 7), the south and southeast exhibit very high and high potential contamination vulnerability. Moreover, from west to east in the central region and part of the northeast exhibit low and very low contamination vulnerability.

Figure 8 indicates that in the hybrid methods, the moderate and low vulnerability areas occupy the most area, i.e., 55.32, 57.02 and $65.08 \%$. The percentage of vulnerable areas in the original DRASTIC map compared with the newly predicted values is higher; nearly half the Kerman plain contains high and very high potential contamination vulnerability. This finding indicates that the enlarged groundwater contamination illustrated by the high and very high vulnerable areas using the DRASTIC model in comparison with the modified models has been optimized in the new methods. Although it can be inferred that the Kerman plain groundwater contamination vulnerability is moderately distributed, the area, 


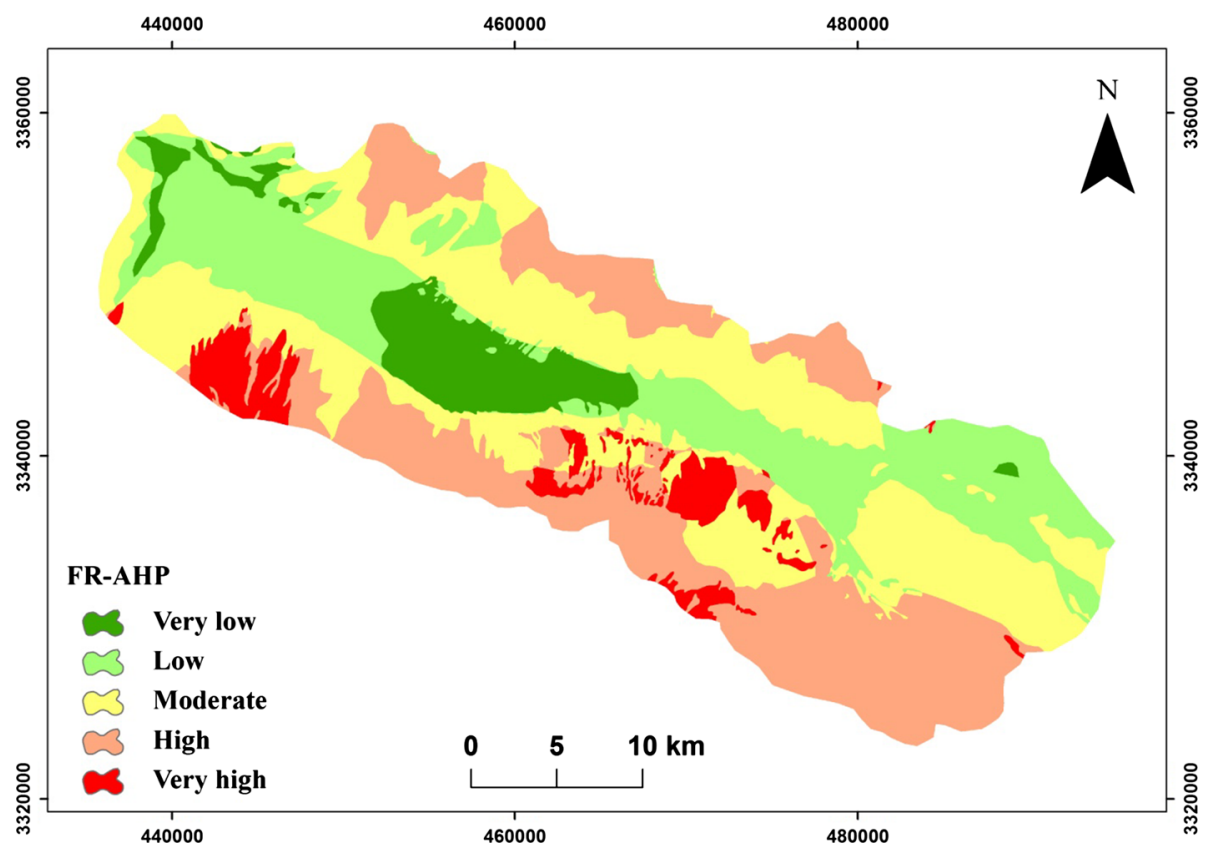

Fig. 7 FR-AHP

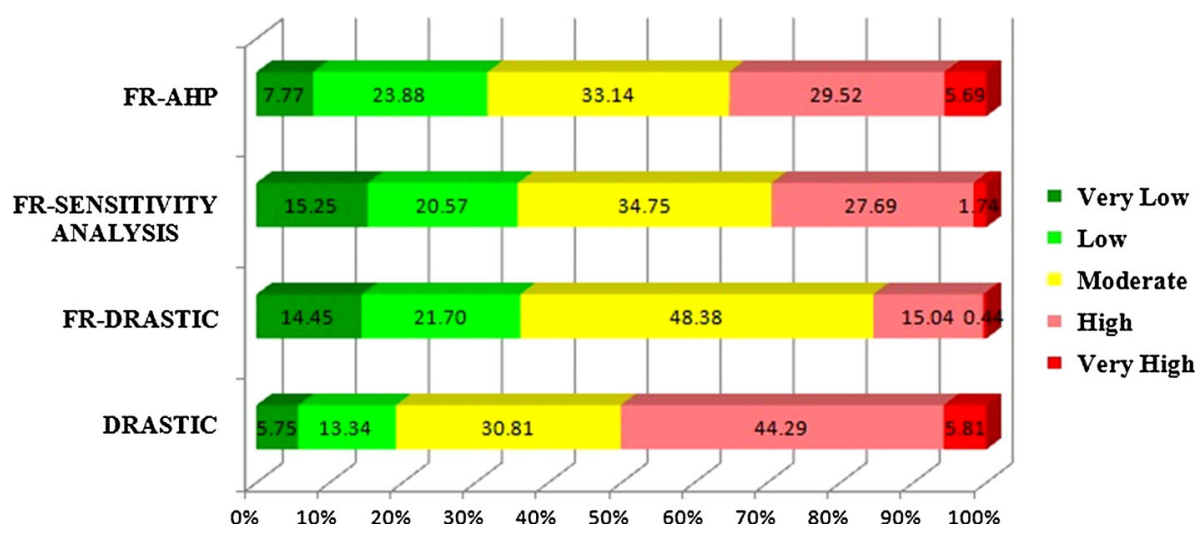

Fig. 8 Comparison of derived vulnerability maps

specifically regarding hydrogeological settings and the extensive agricultural activity, is more susceptible to contamination over time.

4.3 Validation and selection of a suitable method in the study area

The correlation value shows the suitability and reliability of the models applied in the study area. The resultant vulnerability maps were validated using Pearson's correlation factor to select the best vulnerability maps regarding the study area conditions. The FR 
Table 5 Correlation factor comparison

\begin{tabular}{ll}
\hline Vulnerability maps & $\begin{array}{l}\text { Pearson's correlation } \\
\text { coefficient }\end{array}$ \\
\hline DARSTIC & 0.37 \\
FR-DRASTIC & 0.75 \\
FR-SPSA & 0.77 \\
FR-AHP & 0.80
\end{tabular}

approach integrated with other methods played an important role in increasing the correlation between groundwater vulnerability and nitrate concentrations in 2012. The original DRASTIC vulnerability correlation was 0.37 . After optimization, the correlation changed, increasing to 0.75 in the FR-DRASTIC model. Correlations of 0.77 and 0.80 were obtained for the FR-SPSA and FR-AHP approaches (see Table 5). These values suggest that the vulnerability map derived from the FR-AHP method is more accurate. The correlation values for the new hybrid methods are relatively similar. The high vulnerability in the southeastern Kerman plain is common among all methods; this area primarily contains highly permeable gravel and sand.

\section{Conclusion}

Evaluating the potential groundwater contamination is important because groundwater is typically the only water source in arid and semiarid areas. The extensive use of fertilizers for agricultural activities in the study area increases the amount of pollution. The DRASTIC model can be criticized because the chosen features and adopted ratings and weights do not always conform to the study area specifications. Therefore, many studies have developed modified DRASTIC models. Because the DRASTIC model can be evaluated using hydrogeological parameters, this study attempted to use the same volume of data and nitrate concentration to develop a modified DRASTIC model.

The FR approach is used to optimize the rates of DRASTIC parameters in this study. Therefore, new hybrid methods are introduced by first modifying the DRASTIC model rating scale using the FR approach and then integrating with other weighting methods. Because the AHP and SPSA methods are efficient for optimization, they have been applied for parameter weighting. Optimizing the DRASTIC model weights with the AHP and SPSA approaches indicates that the net recharge, soil and vadose zone impact are effective parameters in the Kerman plain.

According to this evaluation, by integrating the original DRASTIC weights with the modified rates, the correlation of the original DRASTIC results sharply doubled with the FR-DRASTIC model. However, this correlation in the FR-SPSA increases gradually. The FR-AHP approach has the higher correlation compared with the other methods with an $80 \%$ correlation.

The groundwater vulnerability mapping for nitrate can be employed for perceptible groundwater resource management. Repeated and accurate monitoring of groundwater quality in relatively high vulnerable areas should be implemented to control changing contaminant levels. The proposed methodologies suggest an effective approach to preserve groundwater resources. This research may also be applied to boost awareness of environmental issues. 
Acknowledgments The authors would like to thank two anonymous reviewers for their valuable critical comments.

\section{References}

Afshar A, Mariño MA, Ebtehaj M, Moosavi J (2007) Rule-based fuzzy system for assessing groundwater vulnerability. J Environ Eng 133(5):532-540

Aller L, Bennet T, Lehr JH, Petty RJ, Hacket G (1985) DRASTIC: a standardized system for evaluating groundwater pollution using hydrological settings. Prepared by the National water Well Association for the US EPA Office of Research and Development

Aller L, Bennet T, Lehr JH, Petty RJ, Hackett G (1987) DRASTIC: a standardized system for evaluating groundwater pollution potential using hydrogeological settings. US Environmental Protection Agency

Althuwaynee OF, Pradhan B, Park HJ, Lee JH (2014) A novel ensemble bivariate statistical evidential belief function with knowledge-based analytical hierarchy process and multivariate statistical logistic regression for landslide susceptibility mapping. Catena 114:21-36

Anane M, Bouziri L, Limam A, Jellali S (2012) Ranking suitable sites for irrigation with reclaimed water in the Nabeul-Hammamet region (Tunisia) using GIS and AHP-multicriteria decision analysis. Resour Conserv Recycl 65:36-46

Antonakos AK, Lambrakis NJ (2007) Development and testing of three hybrid methods for the assessment of aquifer vulnerability to nitrates, based on the drastic model, an example from NE Korinthia, Greece. J Hydrol 333:288-304

Assaf H, Saadeh M (2009) Geostatistical assessment of groundwater nitrate contamination with reflection on DRASTIC vulnerability assessment: the case of the Upper Litani Basin, Lebanon. Water Resour Manage 23:775-796

Baalousha H (2010) Assessment of a groundwater quality monitoring network using vulnerability mapping and geostatistics: a case study from Heretaunga Plains, New Zealand. Agric Water Manag 97:240-246

Babiker I, Mohamed M, Hiyama T, Kato K (2005) A GIS based DRASTIC model for assessing aquifer vulnerability in Kakamigahara Heights, Gifu Prefecture, Central Japan. Sci Total Environ 345:127-140

Boughriba M, Barkaoui AE, Zarhloule Y, Lahmer Z, El Houadi B, Verdoya M (2010) Groundwater vulnerability and risk mapping of the Angad transboundary aquifer using DRASTIC index method in GIS environment. Arab J Geosci 3:207-220

Boy-Roura M, Nolan BT, Menció A, Mas-Pla J (2013) Regression model for aquifer vulnerability assessment of nitrate pollution in the Osona region (NE Spain). J Hydrol 505:150-162

Carvalho GJP, Pacheco FAL (2009) Análise da vulnerabilidade à contaminac, ão das águassubterrâneas na bacia hidrográfica do Rio Sordo (Vila Real) pelo método fuzzy-DRASTIC. Recur Hídricos 31(1):65-76

Chen SK, Jang CS, Peng YH (2013) Developing a probability-based model of aquifer vulnerability in an agricultural region. J Hydrol 486:494-504

Chica-Olmo M, Luque-Espinar JA, Rodriguez-Galiano V, Pardo-Igúzquiza E, Chica-Rivas L (2014) Categorical indicator Kriging for assessing the risk of groundwater nitrate pollution: the case of Vega de Granada aquifer (SE Spain). Sci Total Environ 470:229-239

Chitsazan M, Akhtari Y (2009) A GIS-based DRASTIC model for assessing aquifer vulnerability in Kherran Plain, Khuzestan, Iran. Water Resour Manage 23:1137-1155

Christopher Frey H, Patil SR (2002) Identification and review of sensitivity analysis methods. Risk Anal 22(3):553-578

Demir G, Aytekin M, Akgün A, İkizler SB, Tatar O (2013) A comparison of landslide susceptibility mapping of the eastern part of the North Anatolian Fault Zone (Turkey) by likelihood-frequency ratio and analytic hierarchy process methods. Nat Hazards 65(3):1481-1506

Farjad B, bin Mohd Shafri HZ, Mohamed TA, Pirasteh S, Wijesekara N (2012) Groundwater intrinsic vulnerability and risk mapping. Proc ICE-Water Manage 165(8):441-450

Feizizadeh B, Blaschke T (2013) GIS-multicriteria decision analysis for landslide susceptibility mapping: comparing three methods for the Urmia lake basin, Iran. Nat Hazards 65(3):2105-2128

Fijani E, Nadiri AA, Asghari Moghaddam A, Tsai FTC, Dixon B (2013) Optimization of DRASTIC method by supervised committee machine artificial intelligence to assess groundwater vulnerability for Maragheh-Bonab plain aquifer, Iran. J Hydrol 503:89-100

Focazio MJ, Kolpin DW, Barnes KK, Furlong ET, Meyer MT, Zaugg SD, Barber LB, Thurman ME (2008) A national reconnaissance for pharmaceuticals and other organic wastewater contaminants in the United States-II) Untreated drinking water sources. Sci Total Environ 402:201-216 
Frind EO, Martin P (2004) 3D colour schemes for complex glacial aquifer/aquitard systems. Third workshop on three dimensional geological mapping for groundwater applications GAC/Mac conference. St. Catharines, Ontario: Brock University, Canada

Gogu RC, Hallet V, Dassargues A (2003) Comparison of aquifer vulnerability assessment techniques: application to the Ne'blon river basin (Belgium). Environ Geol 44:881-892. doi:10.1007/s00254-0030842-X

Huan H, Wang J, Teng Y (2012) Assessment and validation of groundwater vulnerability to nitrate based on a modified DRASTIC model: a case study in Jilin City of northeast China. Sci Total Environ 440:14-23

Javadi S, Kavehkar N, Mohammadi K, Khodadi A, Kahawita K (2011) Calibration DRASTIC using field measurements, sensitivity analysis and statistical method to assess groundwater vulnerability. Water Int 36:719-732

Kauffman LJ, Chapelle FH (2010) Relative vulnerability of public supply wells to VOC contamination in hydrologically distinct regional aquifers. Ground Water Monit Remediat 30:54-63

Li R, Merchant JW (2013) Modeling vulnerability of groundwater to pollution under future scenarios of climate change and biofuels-related land use change: a case study in North Dakota, USA. Sci Total Environ 447:32-45

Masetti M, Sterlacchini S, Ballabio C, Sorichetta A, Poli S (2009) Influence of threshold value in the use of statistical methods for groundwater vulnerability assessment. Sci Total Environ 407:3836-3846

Mendes MP, Ribeiro L (2010) Nitrate probability mapping in the northern aquifer alluvial system of the river Tagus (Portugal) using disjunctive Kriging. Sci Total Environ 408:1021-1034

Mishima Y, Takada M, Kitagawa R (2011) Evaluation of intrinsic vulnerability to nitrate contamination of groundwater: appropriate fertilizer application management. Environ Earth Sci 63(3):571-580

Mishra U (2009) Predicting storage and dynamics of soil organic carbon at a regional scale. (Thesis of PhD) Presented in Partial Fulfillment of the Requirement for the Degree of Doctor of Philosophy in the Graduate. School of the Ohio State University

Mohammadi K, Niknam R, Majd VJ (2009) Aquifer vulnerability assessment using GIS and fuzzy system: a case study in Tehran-Karaj aquifer, Iran. Environ Geol 58(2):437-446

Mohammady M, Pourghasemi HR, Pradhan B (2012) Landslide susceptibility mapping at Golestan province, Iran: a comparison between frequency ratio, Dempster-Shafer, and weights-of-evidence models. J Asian Earth Sci 61:221-236

Nampak H, Pradhan B, Manap MA (2014) Application of GIS based data driven evidential belief function model to predict groundwater potential zonation. J Hydrol 513:283-300. doi:10.1016/j.jhydrol.2014. 02.053

Napolitano P, Fabbri AG (1996) Single-parameter sensitivity analysis for aquifer vulnerabiliy assessment using DRASTIC and SINTACS. IAHS Publ-Ser Proc Rep-Intern As Hydrol Sci 235:559-566

Neshat A, Pradhan B, Pirasteh S, Shafri HZM (2013) Estimating groundwater vulnerability to pollution using a modified DRASTIC model in the Kerman agricultural area, Iran. Environ Earth Sci doi: 10. 1007/s12665-013-2690-7

Neshat A, Pradhan B, Dadras M (2014a) Groundwater vulnerability assessment using an improved DRASTIC method in GIS. Resour Conserv Recycl 86:74-86. doi:10.1016/j.resconrec.2014.02.008

Neshat A, Pradhan B, Shafri HZM (2014b) An integrated GIS based statistical model to compute groundwater vulnerability index for decision maker in agricultural area. J Indian Soc Remote Sens 42(4):777-788

Neukum C, Azzam R (2009) Quantitative assessment of intrinsic groundwater vulnerability to contamination using numerical simulations. Sci Total Environ 408:245-254. doi:10.1016/j.scitotenv.2009.09. 046

Nobre RCM, Rotunno OC, Mansur WJ, Nobre MMM, Cosenza CAN (2007) Groundwater vulnerability and risk mapping using GIS, modeling and a fuzzy logic tool. J Contam Hydrol 94:277-292

Nourani V, Pradhan B, Ghaffari H, Sharifi SS (2014) Landslide susceptibility mapping at Zonouz Plain, Iran using genetic programming and comparison with frequency ratio, logistic regression, and artificial neural network models. Nat Hazards 71(1):523-547

Oh HJ, Kim YS, Choi JK, Park E, Lee S (2011) GIS mapping of regional probabilistic groundwater potential in the area of Pohang City, Korea. J Hydrol 399:158-172

Ozdemir A (2011) Using a binary logistic regression method and GIS for evaluating and mapping the groundwater spring potential in the Sultan Mountains (Aksehir, Turkey). J Hydrol 411:290-308

Pacheco FA, Sanches Fernandes LF (2013) The multivariate statistical structure of DRASTIC model. J Hydrol 476:442-459 
Panagopoulos GP, Antonakos AK, Lambrakis NJ (2006) Optimization of the DRASTIC method for groundwater vulnerability assessment via the use of simple statistical methods and GIS. Hydrol J 14:894-911

Pourghasemi HR, Pradhan B, Gokceoglu C (2012) Application of fuzzy logic and analytical hierarchy process (AHP) to landslide susceptibility mapping at Haraz watershed: Iran. Nat Hazards 63(2):965-996

Pradhan B, Lee S (2010a) Delineation of landslide hazard areas on Penang Island, Malaysia, by using frequency ratio, logistic regression, and artificial neural network models. Environ Earth Sci 60:1037-1054

Pradhan B, Lee S (2010b) Regional landslide susceptibility analysis using back-propagation neural network model at Cameron Highland, Malaysia. Landslides 7:13-30

Pradhan B, Lee S, Buchroithner MF (2010) Remote sensing and GIS-based landslide susceptibility analysis and its cross-validation in three test areas using a frequency ratio model. Photogramm, Fernerkund, Geoinf 2010(1):17-32

Rahman A (2008) A GIS based DRASTIC model for assessing groundwater vulnerability in shallow aquifer in Aligarh, India. Appl Geogr 28:32-53

Roodposhti MS, Rahimi S, Beglou MJ (2014) PROMETHEE II and fuzzy AHP: an enhanced GIS-based landslide susceptibility mapping. Nat Hazards 73(1):77-95

Rupert MG (2001) Calibration of the DRASTIC ground water vulnerability mapping method. Groundwater 39(4):625-630

Saaty TL (1980) The analytical hierarchy process. McGraw Hill, New York

Saaty TL, Vargas GL (2001) Models, Methods, Concepts, and Applications of the Analytic Hierarchy Process. Kluwer, Boston

Saidi S, Bouri S, Dhia HB (2010) Groundwater vulnerability and risk mapping of the Hajeb-jelma aquifer (Central Tunisia) using a GIS-based DRASTIC model. Environ Earth Sci 59:1579-1588

Saidi S, Bouri S, Dhia HB, Anselme B (2011) Assessment of groundwater risk using intrinsic vulnerability and hazard mapping: application to Souassi aquifer, Tunisian Sahel. Agric Water Manage 98:1671-1682

Stefanidis S, Stathis D (2013) Assessment of flood hazard based on natural and anthropogenic factors using analytic hierarchy process (AHP). Nat Hazards 68(2):569-585

Stigter TY, Ribeiro L, Dill AMM (2008) Building factorial regression models to explain and predict nitrate concentrations in groundwater under agricultural land. J Hydrol 357:42-56

Umar Z, Pradhan B, Ahmad A, Jebur MN, Tehrany MS (2014) Earthquake induced landslide susceptibility mapping using an integrated ensemble frequency ratio and logistic regression models in West Sumatera province, Indonesia. Catena 118:124-135

USEPA (1996). Indoor air quality basics for schools. United States Environmental Protection Agency

Wang J, He J, Chen H (2012) Assessment of groundwater contamination risk using hazard quantification, a modified DRASTIC model and groundwater value, Beijing Plain, China. Sci Total Environ 432:216-226

Yalcin A, Reis S, Aydinoglu AC, Yomralioglu T (2011) A GIS-based comparative study of frequency ratio, analytical hierarchy process, bivariate statistics and logistics regression methods for landslide susceptibility mapping in Trabzon, NE Turkey. Catena 85:274-287

Youssef AM, Pradhan B, Tarabees E (2011) Integrated evaluation of urban development suitability based on remote sensing and GIS techniques: contribution from the analytic hierarchy process. Arab J Geosci 4(3-4):463-473

Yu C, Yao Y, Hayes G, Zhang B, Zheng C (2010) Quantitative assessment of groundwater vulnerability using index system and transport simulation, Huangshuihe catchment, China. Sci Total Environ 408:6108-6116

Zwahlen F (2004) Vulnerability and risk mapping for the protection of carbonate (karst) aquifers, final report (COST action 620). European Commission, Directorate XII science, research and development, Report EUR 20912, Brussels; p 297 